\title{
OPINION PIECE
}

\section{Quantifying shark predation effects on prey: dietary data limitations and study approaches}

\author{
Neil Hammerschlag ${ }^{1,2, *}$ \\ ${ }^{1}$ Rosenstiel School of Marine and Atmospheric Science, University of Miami, Miami, FL, 33149, USA \\ ${ }^{2}$ Leonard and Jayne Abess Center for Ecosystem Science and Policy, University of Miami, Coral Gables, FL, 33146, USA
}

\begin{abstract}
Understanding the ecological impacts of sharks on prey populations has become a research priority given widespread shark population declines due to overfishing, combined with significant conservation efforts. Accordingly, many studies have conducted analyses of shark stomach contents and/or used biomarkers, such as stable isotope signatures, to assess dietary patterns in order to infer ecological roles. Here, I summarize how relying on stomach contents and/or stable isotope signatures to assess the potential for sharks to initiate trophic cascades can be misleading and may significantly underestimate the strength of shark top-down predation effects on prey. However, a study approach that measures attributes of the sharks (e.g. hunting mode), potential prey (e.g. escape speed) and the environment (e.g. habitat rugosity) can provide greater insights for quantifying the magnitude of top-down predation effects of sharks and the potential for their population declines or recoveries to trigger trophic cascades. To aid future investigations, I provide a set of predictions, based on ecological theory, which would specifically lead to increases in the magnitude of shark predation effects on prey populations. I also present key study approaches currently being employed by researchers to test such predictions.
\end{abstract}

KEY WORDS: Shark $\cdot$ Apex predator $\cdot$ Predation risk $\cdot$ Trophic cascade $\cdot$ Coral reef $\cdot$ Fishing

\section{INTRODUCTION}

Both ecological theory and empirical data demonstrate that predators can affect prey communities, and subsequently initiate trophic cascades, even in the absence of prey consumption (Creel \& Christianson 2008, Estes et al. 2016, Hammerschlag et al. 2019). However, some recent discussions on the ecological roles of sharks have been increasingly focused on aspects of diet (e.g. Grubbs et al. 2016, Roff et al. 2016, Bond et al. 2018). For example, when evaluating for the potential for shark declines to initiate trophic cascades, Grubbs et al. (2016) argued that 5 criteria need to be considered, among them being that prey be a significant part of a predator's diet and also that the predator be the primary source of prey predation mortality.

\footnotetext{
*Corresponding author: nhammerschlag@miami.edu
}

In light of these discussions, the goal of this paper is to evoke relevant ecological theory to demonstrate that relying on dietary information can be misleading when trying to quantify the strength of top-down predation effects of sharks, and consequently, the potential for their population declines or recoveries to initiate trophic cascades. To aid in future investigations into shark ecological roles, I also provide a set of predictions, based on functional attributes of sharks, prey and the environment, which would lead to increases in the magnitude of shark predation effects on prey populations. I also review key study approaches currently being employed to quantify effects of sharks on prey. I note upfront that because the ecological concepts being cited here have already been reviewed elsewhere, I will not do so again in this paper.

() The author 2019. Open Access under Creative Commons by Attribution Licence. Use, distribution and reproduction are unrestricted. Authors and original publication must be credited. 


\section{LIMITATIONS OF DIETARY INFORMATION}

Besides the well known limitations of gut content analyses (reviewed by Baker et al. 2014), there are various reasons why assessments of trophic levels or ecological roles of sharks, in particular, cannot rely primarily on this method. First, shark stomachs are usually empty as they often evert their stomach upon capture for sampling (Brunnschweiler et al. 2011). Second, while sharks and other predators can most obviously affect prey by killing and consuming them, predators can also initiate strong top-down effects on prey even when prey are absent from predator stomachs and the direct predation mortality to prey is zero (reviewed in Creel \& Christianson 2008). This is because antipredator responses of prey, and associated risk effects, will lower direct predation mortality and as a result, prey will be rare or even absent in the stomach of predators (Creel \& Christianson 2008; Fig. 1).

In addition to stomach content analysis, stable isotope signatures of nitrogen $(\mathrm{N})$ and carbon $(\mathrm{C})$ from tissues are increasingly being used to infer trophic niches of sharks (reviewed by Hussey et al. 2012, Shiffman et al. 2012). There are many considerations and limitations when applying this tool to study the trophic ecology of individuals or populations (see reviews by Layman et al. 2012); yet, many studies continue to use isotopic ratios from tissues to estimate trophic position of sharks relative to other species in the community and subsequently infer ecological roles. However, among other possible issues, stable isotope signatures are a long-term integration of resources and it is possible that 2 species can have distinct diets but very similar isotopic signatures, if one consumer's isotopic signature represents the average of 2 isotopically extreme resource bases. This is particularly relevant in the case of sharks since they are opportunistic trophic omnivores, feeding across the food web and among different habitats (Hussey et al. 2012, Shiffman et al. 2012). Accordingly, studies that rely primarily on diet and stable isotope information may underestimate top-down effects of sharks.

In a recent review, Roff et al. (2016) argued that large reef sharks are trophically equivalent to sympatric piscivorous teleosts, such as large groupers and snappers. They further concluded that the removal of reef sharks by humans is therefore unlikely to initiate strong top-down effects on large teleosts and therefore unlikely to trigger trophic cascades. These arguments were largely based on 2 primary lines of reasoning. First, large piscivorous teleosts are often rare or absent in the diet of sampled reef sharks. Second, stable isotope signatures generally overlapped between reef sharks and these large piscivorous teleosts. However, these arguments did not take into account the limitations of relying solely on studies of diet and stable isotopes to infer strengths of top-down predator effects as described above. These limitations are evidenced by recent data which suggest that the targeted removal of large-bodied reef sharks has contributed to changes in the abundance, diversity, diet, condition and morphology of coral reef fishes (Ruppert et al. 2013, 2016, Barley et al. 2017a,b, Hammerschlag et al. 2018).

\section{APPROACHES FOR QUANTIFYING SHARK PREDATION EFFECTS}

Several papers have developed frameworks for determining the strength of predator effects on prey populations. Taken together, these works have shown that functional attributes of the predator (e.g. hunting mode), prey (e.g. grouping) and the environment (e.g. habitat structure) can influence the outcome of predator-prey interactions (Schmitz 2008, Creel 2011, 2018, Schmitz et al. 2017, Gaynor et al. 2019). By synthesizing these works in combination with an understanding of preda-

Fig. 1. Conceptual diagram of how expression of antipredatory responses by prey can increase risk effects of predators, while reducing direct predation mortality (adapted from Creel \& Christianson [2008]). Consider 3 prey species $(\alpha, \beta$, and $\phi)$ that become exposed to increasing densities of predators. In such a scenario, (A) individuals of surviving prey $\alpha, \beta$, and $\phi$ may exhibit antipredatory responses (e.g. induce defensive armor or hiding behavior) that scale with their respective level of encounter rates with attacking predators. However, (B) if $\phi$ increases its expression of antipredator traits effectively, direct predation will decrease on $\phi$ and consequently $\phi$ will become rare or absent in predator diets, although predators still have strong risk effects on $\phi$. Moreover, if antipredatory responses of $\phi$ cause predators to shift their hunting efforts towards $\alpha$ and $\beta$, then $(\mathrm{C})$ direct effects and risk effects can even become negatively correlated 
tor-prey interactions involving sharks based on my own in situ studies, I provide a set of predictions that would specifically lead to increases in the magnitude of shark predation effects on prey, and distinguish whether consumptive or risk effects would dominate these interactions. These are listed in Table 1 and may be useful for identifying potential situations where sharks can affect prey through either consumptive or risk effects.

There are a variety of methodological approaches already being used for measuring relative attributes of sharks, prey and the environment at appropriate scales for assessment of shark predation effects. Relevant shark attributes for investigation include assessing their hunting mode (search and pursuit vs. sit and wait), hunting periods, hunting areas, grouping, feeding rates, and gape size. For example, using underwater visual surveys, Robbins \& Renaud (2016) documented differences in hunting strategies and predation success rate among grey reef sharks, Carharhinus amblyrhynchos, at Fakarava Atoll,
French Polynesia. During morning hours, the sharks targeted spawning grouper, employing burst speed to capture fish engaged in spawning. In contrast, sharks switched prey targets to other fish species at night, employing a slow, controlled approach which minimized the distances between sharks and prey fish prior to any predation attempts (Robbins \& Renaud 2016). These differences in hunting strategy appeared to be related to the mobility of the different species being targeted and the different environmental conditions (day vs. night). When direct observation of shark hunting is not possible, as is usually the case, multi-sensor biotelemetry and biologging tools are particularly valuable for remotely recording this aspect of shark behavior (Hussey et al. 2015). This could include combining shark tracking with accelerometers (Papastamatiou et al. 2018b), predation tags (Halfyard et al. 2017) and animal-borne cameras (Papastamatiou et al. 2018a).

There are numerous relevant behavioral, physiological and morphological attributes for investigating

Table 1. Predicted attributes of sharks, prey and the environment leading to increases in the magnitude of shark top-down predation effects on prey, and whether consumptive effects (CE) or risk effects (RE) dominate these interactions. Predictions developed from synthesizing works of Schmitz (2008), Creel (2011, 2018), Schmitz et al. (2017), and Gaynor et al. (2019), in combination with an understanding of predator-prey interactions involving sharks based on my own experiences

\begin{tabular}{|c|c|}
\hline Focus & Attribute and prediction \\
\hline Shark & $\begin{array}{l}\text { Both RE and CE will be high when sharks hunt in packs or hunt individually, but simultaneously } \\
\text { Both RE and CE will be high when sharks have a sensory advantage over prey (e.g. increased visual } \\
\text { acuity under low light conditions) } \\
\text { Both RE and CE will be high when sharks have a cognitive advantage over prey (e.g. when they exhibit } \\
\text { social learning or can refine hunting strategy over time) } \\
\text { RE will be higher than CE for ambush predatory sharks which require specific forms of habitat for cover } \\
\text { CE will be higher than RE for active or coursing predatory sharks that do not associate with specific forms } \\
\text { of habitat for cover } \\
\text { RE will be higher than CE when sharks are abundant and predictably distributed } \\
\text { CE will be higher than RE when sharks are widespread or rare }\end{array}$ \\
\hline Prey & $\begin{array}{l}\text { RE and CE will be high for prey that do not employ grouping or schooling behavior or during periods } \\
\text { where they exhibit reduced group or school size } \\
\text { RE will be higher than CE in dietary generalists that can shift habitats in response to sharks } \\
\text { CE will be higher than RE in dietary specialists that cannot alter feeding habits in response to sharks } \\
\text { RE will be higher than CE for prey that can alter or adapt morphological traits in response to sharks } \\
\text { CE will be higher than RE for prey that cannot alter or adapt morphological traits in response to sharks } \\
\text { CE will be higher than RE when prey spatially or temporally aggregate to exploit a predictable temporal } \\
\text { resource pulse, such as an ephemeral food source } \\
\text { CE will be higher than RE when prey spatially or temporally aggregate to engage in a critical life history } \\
\text { event that increases population fitness (e.g. spawning or mating) } \\
\text { RE will be higher than CE when prey have advanced cognition and sensory perception }\end{array}$ \\
\hline Environment & $\begin{array}{l}\mathrm{RE} \text { will be higher than } \mathrm{CE} \text { in more heterogenous environments where prey have more options to hide or } \\
\text { take refuge, such as reefs with high rugosity or dense kelp beds that exclude sharks } \\
\mathrm{CE} \text { will be higher than RE in more homogeneous environments were prey have limited options to hide or } \\
\text { take refuge, such as open sand flats } \\
\text { RE will be higher than CE under environmental conditions that offer prey increased ability to detect } \\
\text { predators, such as good water visibility and during daylight hours } \\
\text { CE will be higher than RE under environmental conditions in which prey have reduced ability to detect } \\
\text { predators (e.g. low light, high turbidity) }\end{array}$ \\
\hline
\end{tabular}


antipredatory responses in prey. These include schooling or grouping behavior, escape mode, space or time devoted to vigilance or refuge use, excursion distances and activity space (in 3 dimensions), foraging rates, body mass and condition, movement rate, stress levels, nutritional condition, and morphological structures associated with defense, detection, or evasion. As in the case for sharks, behavioral responses of prey could be measured via observational and/or biotelemetry and biologging tools (Wirsing et al. 2007, Madin et al. 2010, De Vos et al. 2015). For example, using underwater camera monitoring on Australian coral reefs, Atwood et al. (2018) measured grazing rates of herbivorous fishes at varying distances from refuges under threat of predation. Physiological responses of prey could be assessed noninvasively via tissue or scat sampling (Hammerschlag et al. 2017, Oliveira et al. 2017). Morphological responses include measuring shape and size of predatory defense structure (e.g. claws or spines; Miller et al. 2015), detection structures (e.g. eyes, olfactory bulbs; Smith \& Litvaitis 1999, Møller \& Erritzøe 2014), and/or evasive locomotory structures (e.g. flipper or fins; Hammerschlag et al. 2018). Relevant environmental attributes widely found to decrease predation risk include increased habitat complexity (Schmitz 1998), proximity to refuge (Atwood et al. 2018), and visibility (Hammerschlag et al. 2006) as well as decreased depth (Rypel et al. 2007). These environmental attributes can be measured in situ or via remotely sensed data (e.g. Madin et al. 2011).

In terms of an experimental approach, these predator-prey attributes can be investigated under natural conditions in response to temporal and/or spatial variation of hunting sharks (e.g. Wirsing et al. 2007, Hammerschlag et al. 2012) or with introduced model sharks (Madin et al. 2010, Rizzari et al. 2014). An emerging opportunity are comparisons over time or between areas exposed to differences in targeted shark removals or protections (e.g. Barley et al. $2017 a, b$, Speed et al. 2018). In addition to these fieldbased approaches, mesocosom or laboratory experimentation of prey reactions to predators are valuable for understanding the often cryptic nature of interactions between shark and their prey (Bedore et al. 2015, Barrios-O'Neill et al. 2017, Stump et al. 2017).

\section{CONCLUSION}

In summary, relying on stomach contents and/or stable isotope signatures to assess the potential for sharks to initiate trophic cascades can be misleading and may significantly underestimate the strength of shark topdown predation effects on prey. A study approach that measures relevant functional attributes of sharks, prey and the environment can provide greater insights for quantifying the magnitude of top-down predation effects (Schmitz 2008, Creel 2011, 2018, Schmitz et al. 2017, Gaynor et al. 2019) and the potential for shark population declines or recoveries to trigger trophic cascades. As outlined by Ruppert et al. (2016), there is a need for research efforts to focus on predator-prey relations (rather than simply the ecology of the predator) to understand the process of predation.

Acknowledgements. Thanks to Brendan Godley, who encouraged me to submit this work, and to the anonymous reviewers whose comments helped significantly strengthen this paper. I also thank the many great colleagues whose research laid the groundwork for this paper and enabled me to synthesize the ideas presented.

\section{LITERATURE CITED}

Atwood TB, Madin EMP, Harborne AR, Hammill E and others (2018) Predators shape sedimentary organic carbon storage in a coral reef ecosystem. Front Ecol Evol 6:110

Baker R, Buckland A, Sheaves M (2014) Fish gut content analysis: robust measures of diet composition. Fish Fish 15:170-177

Barley SC, Meekan MG, Meeuwig JJ (2017a) Diet and condition of mesopredators on coral reefs in relation to shark abundance. PLOS ONE 12:e0165113

* Barley SC, Meekan MG, Meeuwig JJ (2017b) Species diversity, abundance, biomass, size and trophic structure of fish on coral reefs in relation to shark abundance. Mar Ecol Prog Ser 565:163-179

Barrios-O'Neill D, Bertolini C, Collins PC (2017) Trophic cascades and the transient keystone concept. Biol Conserv 212:191-195

Bedore CN, Kajiura SM, Johnsen S (2015) Freezing behaviour facilitates bioelectric crypsis in cuttlefish faced with predation risk. Proc R Soc B 282:20151886

Bond ME, Valentin-Albanese J, Babcock EA, Hussey NE, Heithaus MR, Chapman DD (2018) The trophic ecology of Caribbean reef sharks (Carcharhinus perezi) relative to other large teleost predators on an isolated coral atoll. Mar Biol 165:67

Brunnschweiler JM, Nielsen F, Motta P (2011) In situ observation of stomach eversion in a line-caught shortfin mako (Isurus oxyrinchus). Fish Res 109:212-216

* Creel S (2011) Toward a predictive theory of risk effects: hypotheses for prey attributes and compensatory mortality. Ecology 92:2190-2195

Creel S (2018) The control of risk hypothesis: reactive vs. proactive antipredator responses and stress mediated vs. food mediated costs of response. Ecol Lett 21:947-956

Creel S, Christianson D (2008) Relationships between direct predation and risk effects. Trends Ecol Evol 23:194-201

*De Vos A, O'Riain JM, Meyer MA, Kotze PGH, Kock AA (2015) Behavior of Cape fur seals (Arctocephalus pusillus pusillus) in relation to temporal variation in predation 
risk by white sharks (Carcharodon carcharias) around a seal rookery in False Bay, South Africa. Mar Mamm Sci 31:1118-1131

Estes JA, Heithaus M, McCauley DJ, Rasher DB, Worm B (2016) Megafaunal impacts on structure and function of ocean ecosystems. Annu Rev Environ Resour 41: 83-116

* Gaynor KM, Brown JS, Middleton AD, Power ME, Brashares JS (2019) Landscapes of fear: spatial patterns of risk perception and response. Trends Ecol Evol (in press), doi: 10.1016/j.tree.2019.01.004

* Grubbs RD, Carlson JK, Romine JG, Curtis TH and others (2016) Critical assessment and ramifications of a purported marine trophic cascade. Sci Rep 6:20970

Halfyard EA, Webber D, Del Papa J, Leadley T, Kessel ST, Colborne SF, Fisk AT (2017) Evaluation of an acoustic telemetry transmitter designed to identify predation events. Methods Ecol Evol 8:1063-1071

*Hammerschlag N, Martin RA, Fallows C (2006) Effects of environmental conditions on predator-prey interactions between white sharks (Carcharodon carcharias) and Cape fur seals (Arctocephalus pusillus pusillus) at Seal Island, South Africa. Environ Biol Fishes 76:341-350

*Hammerschlag N, Luo J, Irschick DJ, Ault JS (2012) A comparison of spatial and movement patterns between sympatric predators: bull sharks (Carcharhinus leucas) and Atlantic tarpon (Megalops atlanticus). PLOS ONE 7: e45958

*Hammerschlag N, Meÿer M, Seakamela SM, Kirkman S, Fallows C, Creel S (2017) Physiological stress responses to natural variation in predation risk: evidence from white sharks and seals. Ecology 98:3199-3210

Hammerschlag N, Barley SC, Irschick DJ, Meeuwig JJ, Nelson ER, Meekan MG (2018) Predator declines and morphological changes in prey: evidence from coral reefs depleted of sharks. Mar Ecol Prog Ser 586:127-139

*Hammerschlag N, Schmitz OJ, Flecker AS, Lafferty KD and others (2019) Ecosystem function and services of aquatic predators in the anthropocene. Trends Ecol Evol (in press), doi:10.1016/j.tree.2019.01.005

Hussey NE, MacNeil MA, Olin JA, McMeans BC, Kinney MJ, Chapman DD, Fisk AT (2012) Stable isotopes and elasmobranchs: tissue types, methods, applications and assumptions. J Fish Biol 80:1449-1484

*Hussey NE, Kessel ST, Aarestrup K, Cooke SJ and others (2015) Aquatic animal telemetry: a panoramic window into the underwater world. Science 348:1255642

Layman CA, Araujo MS, Boucek R, Hammerschlag Peyer CM and others (2012) Applying stable isotopes to examine food web structure: an overview of analytical tools. Biol Rev Camb Philos Soc 87:545-562

* Madin EMP, Gaines SD, Warner RR (2010) Field evidence for pervasive indirect effects of fishing on prey foraging behavior. Ecology 91:3563-3571

*Madin EMP, Madin JS, Booth DJ (2011) Landscape of fear visible from space. Sci Rep 1:14

Miller SE, Metcalf D, Schluter D (2015) Intraguild predation leads to genetically based character shifts in the threespine stickleback. Evolution 69:3194-3203

Møller AP, Erritzøe J (2014) Predator-prey interactions,

Editorial responsibility: Brendan Godley,

University of Exeter, Cornwall Campus, UK flight initiation distance and brain size. J Evol Biol 27: $34-42$

* Oliveira TA, Idalencio R, Kalichak F, dos Santos Rosa JG and others (2017) Stress responses to conspecific visual cues of predation risk in zebrafish. PeerJ 5:e3739

Papastamatiou YP, Meyer CG, Watanabe YY, Heithaus MR (2018a) Animal-borne video cameras and their use to study shark ecology and conservation. In: Carrier JC, Heithaus MR, Simpfendorfer CA (eds) Shark research: emerging technologies and applications for the field and laboratory. CRC Press, Boca Raton, FL, p 83-92

* Papastamatiou YP, Watanabe YY, Demšar U, Leos-Barajas V and others (2018b) Activity seascapes highlight central place foraging strategies in marine predators that never stop swimming. Mov Ecol 6:9

* Rizzari JR, Frisch AJ, Hoey AS, McCormick MI (2014) Not worth the risk: apex predators suppress herbivory on coral reefs. Oikos 123:829-836

Robbins WD, Renaud P (2016) Foraging mode of the grey reef shark, Carcharhinus amblyrhynchos, under two different scenarios. Coral Reefs 35:253-260

* Roff G, Doropulos C, Rogers A, Priest M and others (2016) The ecological role of sharks on coral reefs. Trends Ecol Evol 31:395-407

* Ruppert JLW, Travers MJ, Smith LL, Fortin MJ, Meekan MG (2013) Caught in the middle: combined impacts of shark removal and coral loss on the fish communities of coral reefs. PLOS ONE 8:e74648

Ruppert JLW, Fortin MJ, Meekan MG (2016) The ecological role of sharks on coral reefs: response to Roff et al. Trends Ecol Evol 31:586-587

* Rypel AL, Layman CA, Arrington DA (2007) Water depth modifies relative predation risk for a motile fish taxon in Bahamian tidal creeks. Estuaries Coasts 30:518-525

* Schmitz OJ (1998) Direct and indirect effects of predation and predation risk in old field interaction webs. Am Nat 151:327-342

* Schmitz OJ (2008) Effects of predator hunting mode on grassland ecosystem function. Science 319:952-954

Schmitz OJ, Miller JR, Trainor AM, Abrahms B (2017) Toward a community ecology of landscapes: predicting multiple predator-prey interactions across geographic space. Ecology 98:2281-2292

* Shiffman DS, Gallagher AJ, Boyle MD, HammerschlagPeyer CM, Hammerschlag N (2012) Stable isotope analysis as a tool for elasmobranch conservation research: a primer for non-specialists. Mar Freshw Res 63:635-643

Smith DF, Litvaitis JA (1999) Differences in eye size and predator-detection distances of New England and eastern cottontails. Northeast Wildl 54:55-60

* Speed CW, Cappo M, Meekan MG (2018) Evidence for rapid recovery of shark populations within a coral reef marine protected area. Biol Conserv 220:308-319

* Stump KL, Crooks CJ, Fitchett MD, Gruber SH, Guttridge TL (2017) Hunted hunters: an experimental test of the effects of predation risk on juvenile lemon shark habitat use. Mar Ecol Prog Ser 574:85-95

*Wirsing AJ, Heithaus MR, Dill LM (2007) Fear factor: Do dugongs (Dugong dugon) trade food for safety from tiger sharks (Galeocerdo cuvier)? Oecologia 153:1031-1040

Submitted: November 15, 2018; Accepted: February 13, 2019 Proofs received from author(s): March 13, 2019 